\title{
Análise da gênese pluvial a partir da aplicação da técnica Spatial Synoptic Classification na região leste do estado do Paraná
}

\author{
Rainfall genesis analysis through the application of Spatial Synoptic Classification technique in the eastern region of the \\ Paraná State
}

\section{Paulo Miguel de Bodas Terassi * $\varangle$ (D) Emerson Galvani $\varangle$ (D)}

\author{
Departamento de Geografia, Faculdade de Filosofia, Letras e Ciências Humanas, \\ Universidade de São Paulo, São Paulo, SP, Brasil \\ E-mail: egalvani@usp.br \\ *E-mail para correspondência: pmbterassi@gmail.com
}

Recebido (Received): 10/05/2021 Aceito (Accepted): 17/11/2021

\begin{abstract}
Resumo: A análise integrada dos atributos climáticos é imprescindível para o conhecimento da dinâmica e dos mecanismos atmosféricos responsáveis pela geração de chuvas em uma determinada região. Portanto, este trabalho objetivou analisar as características atmosféricas predominantes e estabelecer os tipos de tempo responsáveis pela gênese pluviométrica a partir da aplicação da Spatial Synoptic Classification (SCC) em Castro, Curitiba e Paranaguá, situadas no setor leste do estado do Paraná. Foram utilizados os dados de quatro observações diárias de temperatura do $\operatorname{ar}\left({ }^{\circ} \mathrm{C}\right)$, temperatura do ponto de orvalho $\left({ }^{\circ} \mathrm{C}\right)$, umidade relativa do ar $(\%)$, direção $\left({ }^{\circ}\right)$ e velocidade do vento $(\mathrm{m} / \mathrm{s})$, pressão atmosférica $(\mathrm{hPa})$ e nebulosidade (décimos de cobertura de céu) das estações meteorológicas de Castro, Curitiba e Paranaguá, pertencentes ao Instituto Nacional de Meteorologia, para o período de 2007 a 2015. Os tipos de tempo Tropical Úmido, Tropical Úmido Plus e Tropical Úmido 2x Plus ocorreram com maior frequência em Paranaguá em relação às demais localidades devido à influência da maritimidade em condicionar o aumento da umidade relativa do ar. Os tipos de tempo polares ocorreram com maior frequência entre o final de abril e o final de julho em todas as estações meteorológicas, associadas à atuação à mais frequente da massa Polar atlântica e à Frente Polar Atlântica. Em síntese, a SCC demonstrou que os tipos de tempo mais úmidos se dão com maior frequência em Paranaguá, devido à maritimidade, e em Castro e Curitiba, as tipologias indicaram uma maior frequência dos tipos de tempo associados aos sistemas atmosféricos extratropicais.
\end{abstract}

Palavras-chave: Precipitação pluviométrica; Dinâmica atmosférica; Tipos de tempo.

Abstract: The integrated analysis of climatic attributes is essential for the knowledge of atmospheric dynamics and atmospheric mechanisms responsible for the rainfall generation in a certain region. Therefore, this paper aimed to analyze the prevailing atmospheric characteristics and determinate the weather types responsible for rainfall genesis by application of the Spatial Synoptic Classification (SCC) in Castro, Curitiba and Paranaguá, located in the eastern of the Paraná State. Was used the data from four daily observations of air temperature $\left({ }^{\circ} \mathrm{C}\right)$, dew point temperature $\left({ }^{\circ} \mathrm{C}\right)$, relative air humidity $(\%)$, direction $\left(^{\circ}\right)$ and wind speed $(\mathrm{m} / \mathrm{s})$, atmospheric pressure $(\mathrm{hPa})$ and cloudiness (tenths of sky coverage) of the Castro, Curitiba and Paranaguá meteorological stations, belonging to the National Institute of Meteorology, during the period from 2007 to 2015. The weather types Tropical Humid, Tropical Humid Plus and Tropical Humid $2 x$ Plus occurred more frequently in Paranagua compared to the other locations due to the influence of maritimity, resulting in an increase of the relative air humidity. Polar weather types occurred most frequently between the end of April and the end of July in all meteorological stations, associated with the Atlantic polar mass and the Atlantic Polar Front performances. In short, SCC shows that the wetter types of weather occur more frequently in Paranaguá, due to the maritime effect, and in Castro and Curitiba, the typologies indicated a higher frequency of the weather types associated with extratropical atmospheric systems.

Keywords: Rainfall; Atmospheric dynamics; Weather types. 


\section{Introdução}

A análise integrada dos atributos climáticos é imprescindível para o conhecimento da dinâmica e dos mecanismos atmosféricos responsáveis pela geração de chuvas em uma dada região (FONTÃO; ZAVATINI, 2017). Nesta perspectiva, esta pesquisa apoiou-se na investigação conjugada dos atributos climáticos e que possibilitasse avaliar as características da dinâmica atmosférica regional e, sobretudo, suas associações com a gênese da precipitação pluviométrica no setor leste do estado do Paraná, região caracterizada marcadamente pelo clima Subtropical da região Sul do Brasil (KELLER FILHO et al., 2005; FRITZSONS et al., 2011; NERY; CARFAN, 2014; WREGE et al., 2016; NASCIMENTO-JÚNIOR et al., 2020).

Buscou-se, portanto, a utilização de uma metodologia que possibilitasse a análise sintética dos atributos climáticos para a classificação dos tipos de tempo prevalecentes para a ocorrência da precipitação pluvial na área de estudo selecionada em uma série temporal superior àquelas habitualmente avaliadas pela consagrada Análise Rítmica (MONTEIRO, 1971). Deste modo, ao examinar as metodologias com a finalidade descrita acima, optou-se pela Spatial Synoptic Classification (SCC), com potencialidade de denominar os tipos de tempo e suas associações com a gênese pluviométrica para uma série temporal mais extensa em comparação aos demais procedimentos metodológicos (YARNAL et al., 2001; HONDULA et al., 2009; HONDULA; DAVIS, 2011; URBAN; KYSELÝ, 2015).

A metodologia da SSC tem sido amplamente utilizada para diferentes finalidades em várias regiões do Mundo. A SCC se tornou um dos principais procedimentos para a identificação dos tipos de tempo em um amplo conjunto de investigações climatológicas, dentre as quais estão as seguintes: a análise da variabilidade da qualidade do ar; saúde humana; crescimento da vegetação; precipitação e tendências de queda de neve; as mais amplas análises da variabilidade e tendências climáticas e as projeções futuras (HONDULA et al., 2014). Sheridan e Kalkstein (2010) aplicaram a metodologia da SSC para encontrar as relações entre os tipos de tempo, a variabilidade sazonal da temperatura e a mortalidade por ondas de calor em diferentes áreas metropolitanas dos Estados Unidos da América. Vanos et al. (2013) investigaram a relação entre a poluição do ar e a mortalidade entre idosos em diferentes tipos de tempo em localidades do Canadá e, a partir da aplicação da SSC, constaram que as mudanças das condições de tempo afetam diretamente a associação entre os poluentes atmosféricos e a mortalidade.

Os estudos de Leathers et al. (2002) haviam apontado que as anomalias da cobertura de neve na América do Norte estão fortemente associadas a mudanças na frequência de massas de ar sobre o leste do referido continente. Dyer e Mote (2007) apontaram uma diminuição substancial na extensão da cobertura e da profundidade da neve na América do Norte e, baseando-se na SSC, observaram que o aumento da frequência de massas de ar seco moderado em vez da prevalência do ar úmido polar explica o aumento no fluxo de calor sensível e do aumento da ablação nival. Nesta perspectiva, Leung e Gough (2015) mostraram um expressivo e significativo aumento das temperaturas em diferentes localidades do território canadense, condição associada à diminuição significativa da participação dos tipos de tempo DP (Dry Polar) para a dominância do MP (Moist Polar).

Com a utilização da SSC, Armond (2014) caracterizou os tipos de tempo responsáveis pelas condições atmosféricas propícias para a ocorrência dos episódios e eventos extremos pluviométricos na cidade do Rio de Janeiro. Para a análise dos tipos de tempo e a gênese pluvial, este método de classificação climática foi utilizado anteriormente para os dados dos Estados Unidos (SHERIDAN, 2002) e da Europa Ocidental (BOWER et al., 2007) e, mais recentemente, foi empregada para a cidade de São Paulo por Fontão et al. (2018). Este estudo para a capital paulistana destacou a eficácia deste procedimento metodológico para avaliar as condições atmosféricas em um período mais extenso e, contudo, destacam as limitações do emprego da SSC devido ao fato de que este método atribui classes de tipos de tempo a partir de variáveis climáticas por meio de um software e desconsidera aspectos como a análise das cartas sinóticas e da circulação atmosférica local (FONTÃO et al., 2018).

A área de estudo corresponde ao setor mais densamente povoado e urbanizado do estado do Paraná por abrigar a capital, Curitiba, com uma população estimada superior a 1,9 milhão de habitantes, e sua Região Metropolitana, que apresenta uma população estimada superior a 3,8 milhões de habitantes (IBGE, 2020). Além do mais, esta região é singularmente caracterizada pelos tipos de tempos inerentes ao clima Subtropical e se destaca por apresentar como característica singular frente à dinâmica atmosférica do território nacional, mesmo que não exclusiva, da atuação da massa Polar Atlântica (mPa) e do sistema frontal denominado de Frente Polar Atlântica (FPA), conforme apontado por Reboita et al. (2010), Borsato e Mendonça (2015) e Cardozo et al. (2015). 
Considerando-se a relevância da investigação climatológica para a área em estudo a partir da aplicação da SCC, esta pesquisa objetivou analisar as características atmosféricas predominantes e estabelecer os tipos de tempo responsáveis pela gênese pluviométrica a partir da aplicação da SCC em Castro, Curitiba e Paranaguá, situadas no setor leste do estado do Paraná, com vistas a atender lacunas relacionadas ao conhecimento dos mecanismos atmosféricos atuantes neste setor do Brasil Meridional.

\section{A área de estudo}

Os municípios de Curitiba e Castro situam-se no setor leste do estado do Paraná, sendo que o primeiro está integralmente no Primeiro Planalto Paranaense, enquanto o segundo se localiza na transição do Primeiro para o Segundo Planalto Paranaense (MAACK, 2012). Por sua vez, o município de Paranaguá também está situado no leste paranaense, especificamente na Planície Litorânea, conforme indica a Figura 1.

Segundo os dados fornecidos pelo Instituto Nacional de Meteorologia (INMET, 2018), Castro e Curitiba apresentam uma pluviosidade média anual de $1.469,9 \mathrm{~mm}$ e $1.507,4 \mathrm{~mm}$, respectivamente, seguidos da mesma temperatura média anual de $16,8^{\circ} \mathrm{C}$, caracterizando-se pelo tipo climático "Cfb", Subtropical mesotérmico úmido, conforme a classificação climática de Köppen (1936) realizada por Álvares et al. (2013). Mello et al. (2017) descreveram que Paranaguá caracteriza-se por uma pluviosidade média anual de $2.130,1 \mathrm{~mm}$ e pela temperatura média anual de $21,3^{\circ} \mathrm{C}$, o que designa o tipo climático "Cfa", Subtropical quente úmido (JORGE; MENDONÇA, 2017).

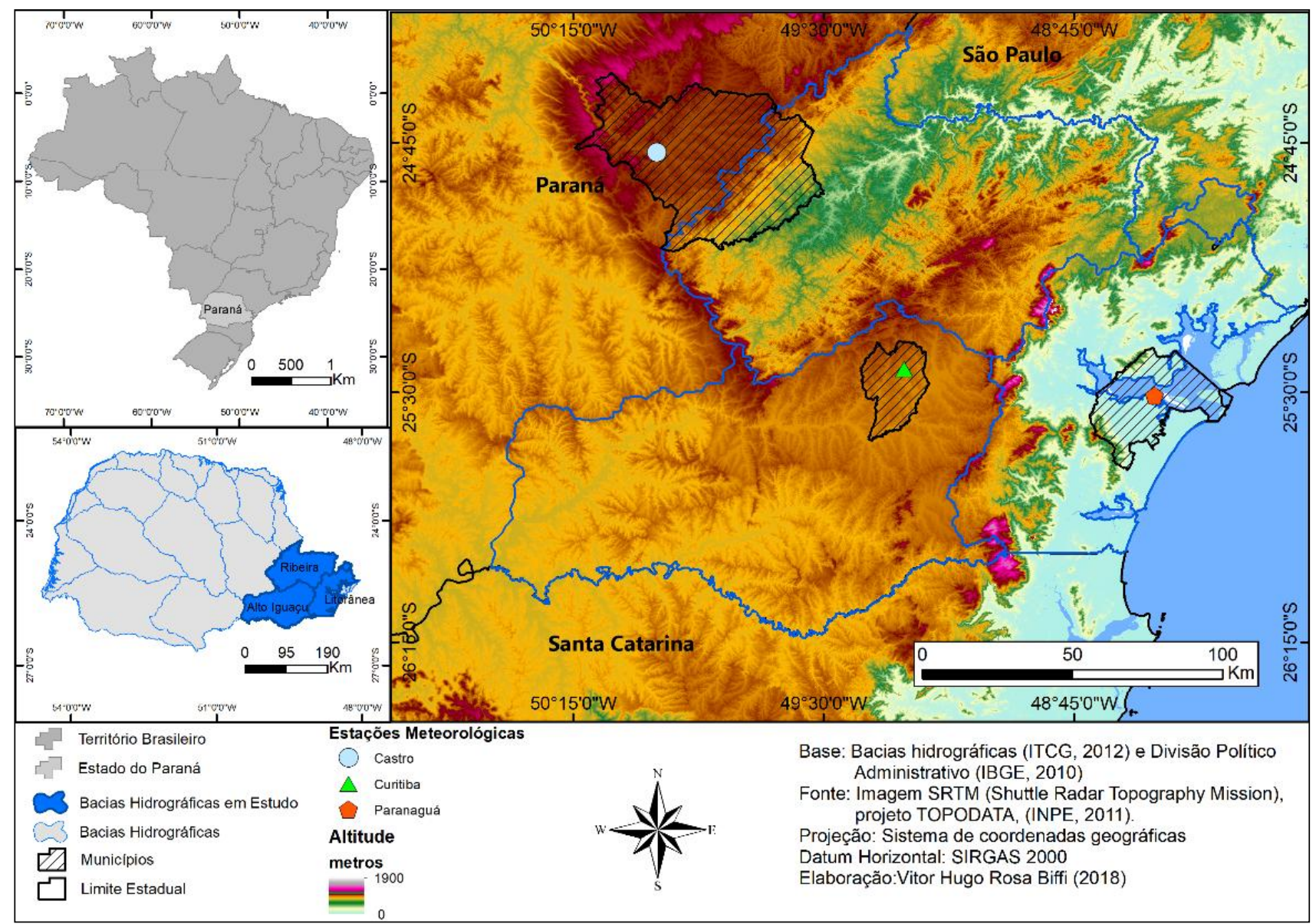

Figura 1. Localização da área de estudo e as respectivas estações meteorológicas automáticas.

\section{Materiais e métodos}

Foram utilizados os dados de quatro observações diárias nos horários sinóticos padrão das $06,12,18$ e 00 horas UTM (3h, 9h, 15h e $21 \mathrm{~h}$ no horário oficial de Brasília) de temperatura do ar $\left({ }^{\circ} \mathrm{C}\right)$, temperatura do ponto de orvalho $\left({ }^{\circ} \mathrm{C}\right)$, umidade relativa do ar $(\%)$, direção $\left({ }^{\circ}\right)$ e velocidade do vento $(\mathrm{m} / \mathrm{s})$, pressão atmosférica (hPa) das estações meteorológicas automáticas de Castro, Curitiba e Paranaguá (Figura 1), que são 
pertencente ao Instituto Nacional de Meteorologia (INMET), para o segmento temporal de 2007 a 2015. Os gráficos desenvolvidos ao longo desta pesquisa foram realizados a partir do software Microsoft Office Excel 2007.

Destaca-se que os dados referentes à nebulosidade (décimos de cobertura do céu) foram registrados pelas estações meteorológicas convencionais situadas nas proximidades das estações meteorológicas automáticas supracitadas e igualmente pertencentes ao INMET. As definições dos decêndios seguiram a organização em conformidade ao decorrer do mês, ou seja, entre os dias 01 e 10 estabeleceu-se o primeiro decêndio, entre os dias 11 e 20 definiu-se o segundo decêndio e entre os dias 21 ao último dia dos meses delimitou-se como o terceiro decêndio, conforme indicam Cupolillo et al. (2008). Como uma restrição, devido à automatização dos resultados gerados a partir da utilização do software SSC, os resultados para o mês de fevereiro foram arbitrariamente definidos como os demais meses do ano.

Os tipos de tempo para a escala decendial e anual, ao longo do período de 2007 a 2015, foram avaliados pelo software Spatial Synoptic Classification (SSC), desenvolvido por Kalkstein et al. (1996) e aprimorado por Kalkstein et al. (1998) e Sheridan (2002). Este procedimento metodológico está próximo à concepção climática da análise rítmica de Monteiro (1971), haja vista que a sua proposição admite a integração entre o processo interativo entre a circulação atmosférica e os atributos climáticos. Contudo, trata-se de um método híbrido, uma vez que a adoção do "seed day" é aprimorado empiricamente a partir da realidade climática local, buscando além de auxiliar na identificação do "dia-semente", aumentar a coesão espacial dos tipos de tempo.

Os dados climáticos são quantificados por meio dos parâmetros e algoritmos propostos por Sheridan (2002) e a variação dos atributos é determinada para cada época do ano (sazonalidade), enfatizando-se que o principal critério estabelecido para a definição dos tipos de tempo é a temperatura do ponto de orvalho. Desta forma, considerou-se como parâmetro os resultados para as cidades de São Paulo (FONTÃO et al., 2018) e do Rio de Janeiro (ARMOND, 2014) para os ajustes finais na elaboração dos parâmetros de cada "seed day".

Assim, foram estabelecidos os limiares mais próximos ao padrão dos atributos climáticos, para a definição de seis tipos de tempo tradicionais: Dry Moderate (DM), Dry Polar (DP), Dry Tropical (DT), Moist Moderate (MM), Moist Polar (MP) e Moist Tropical (MT). Foram estabelecidas as classificações Moist Tropical Plus (MT+) e Moist Tropical Double Plus (MT++), que apesar de tratarem-se de variações do tipo de tempo MT, apresentam temperaturas ainda mais elevadas que as do tipo original (MT). O tipo de tempo representa a alternância e não estão contemplados nas categorias anteriores foram denominados de Transicional (TR). Maiores detalhes estão descritos no Tabela 1 e em Sheridan (2002).

Tabela 1: Categorias de tipos de tempo (weather-types) classificados através do método SSC.

\begin{tabular}{|c|c|c|c|}
\hline Código & Nome & Tradução & Descrição \\
\hline DP & Dry Polar & Polar Seco & $\begin{array}{l}\text { Tipo de tempo frio e seco, aliada à pouca nebulosidade. A ocorrência desse } \\
\text { tipo de tempo à atuação do Anticiclone Polar migratório em sua trajetória } \\
\text { mais continental. }\end{array}$ \\
\hline DM & Dry Moderate & $\begin{array}{l}\text { Moderado } \\
\text { Seco }\end{array}$ & $\begin{array}{l}\text { Tipo de tempo relativamente quente e seco, com nebulosidade moderada. } \\
\text { Está associado às alterações e reestruturação do ar atmosférico das massas } \\
\text { polar e tropical atlântica em seu movimento migratório à área de estudo. }\end{array}$ \\
\hline DT & Dry Tropical & $\begin{array}{l}\text { Tropical } \\
\text { Seco }\end{array}$ & $\begin{array}{l}\text { Tipo de tempo muito quente e de baixa umidade relativa do ar, } \\
\text { manifestando pouca ou nenhuma nebulosidade. Está associado à atuação } \\
\text { de massas de ar estáveis tropicais. }\end{array}$ \\
\hline MP & Moist Polar & Polar Úmido & $\begin{array}{l}\text { Tipo de tempo frio, úmido e com alta nebulosidade. Trata-se da incursão } \\
\text { modificada do ar de origem polar, com a diminuição das temperaturas e a } \\
\text { instabilidade atmosférica. }\end{array}$ \\
\hline MM & $\begin{array}{l}\text { Moist } \\
\text { Moderate }\end{array}$ & $\begin{array}{l}\text { Moderado } \\
\text { Úmido }\end{array}$ & $\begin{array}{l}\text { Temperaturas relativamente quentes e a umidade do ar moderadamente } \\
\text { elevada, podendo resultar em aumento da nebulosidade e, em alguns casos, } \\
\text { precipitação. }\end{array}$ \\
\hline MT & $\begin{array}{l}\text { Moist } \\
\text { Tropical }\end{array}$ & $\begin{array}{l}\text { Tropical } \\
\text { Úmido }\end{array}$ & $\begin{array}{l}\text { Tipo de tempo quente, bastante úmido e de elevada nebulosidade. Está } \\
\text { associado à atuação de massas de ar tropicais, em alguns casos com linhas } \\
\text { de instabilidade, ou em setores quentes de uma frente. }\end{array}$ \\
\hline
\end{tabular}




\begin{tabular}{llll} 
MT+ + Moist Tropical & $\begin{array}{l}\text { Tropical } \\
\text { Plus } \\
\text { Mais }\end{array}$ & $\begin{array}{l}\text { Adotado para classificar dias mais quentes na região intertropical. } \\
\text { Diferencia-se por apresentar temperaturas mais elevadas que o "seed day" } \\
\text { durante a manhã e a tarde. }\end{array}$ \\
TR & $\begin{array}{l}\text { Moist } \\
\text { Tropical } \\
\text { Double Plus }\end{array}$ & $\begin{array}{l}\text { Tropical } \\
\text { Úmido } \\
\text { Duplo Mais }\end{array}$ & $\begin{array}{l}\text { Classifica os dias de com temperaturas ainda mais elevadas que o MT+. } \\
\text { Diferencia-se por apresentar temperaturas de ao menos um desvio padrão } \\
\text { acima do "seed day", tanto na média da manhã quanto da tarde. }\end{array}$ \\
\hline Transitional & Transicional & $\begin{array}{l}\text { Dias em que as condições atmosféricas não são compreendidas nas classes } \\
\text { anteriores, havendo mudanças sensíveis nos limiares de pressão, ponto de } \\
\text { orvalho e vento ao longo do dia. }\end{array}$ \\
\hline
\end{tabular}

Fontes: Sheridan (2002), Armond (2014) e Fontão et al. (2018).

\section{Resultados e discussão}

Os resultados da aplicação da técnica SSC para Castro demonstra que o tipo de tempo mais frequente entre os primeiros dias de setembro e o último decêndio de março, com exceção do segundo decêndio de dezembro e o primeiro decêndio de março, é o MM (moderado úmido), caracterizando-se pela principal condição atmosférica predominante no período mais chuvoso nesta localidade, condição próxima à observada por Fontão et al. (2018) para a cidade de São Paulo. O mês mais seco da série histórica, agosto destaca-se pela participação do tipo de tempo DM (Moderadamente Seco), com valores superiores a 20\% nos três decêndios deste mês e, contudo, o período que este tipo de tempo é mais frequente é o primeiro decêndio de março $(35,6 \%)$, como observa-se pela Figura $2 \mathrm{~A}$.

Verifica-se, contudo, que ao longo do inverno há o aumento significativo dos tipos de tempo associados às entradas da Frente Polar Atlântica (FPA) e a massa de ar Polar atlântica (mPa), com os tipos de tempo mais frequentes MP (polar úmido) e DP (polar seco), nesta ordem. Observa-se que o tipo de tempo MP atinge o percentual de $44,4 \%$ dos tipos de tempo observados para a segunda semana de maio, associados às condições de frio, umidade e alta nebulosidade, ao passo que no segundo decêndio de janeiro há a menor frequência $(1,1 \%)$. O tipo de tempo DP é mais frequente no primeiro decêndio de maio $(25,6 \%)$ e de junho $(22,2 \%)$, sendo que sua menor frequência relativa ocorre no último decêndio de dezembro $(1,0 \%)$. Os tipos de tempo de transição (TR) foram mais frequentes $(>19,0 \%)$ no segundo decêndio de fevereiro e nos terceiros decêndios dos meses de novembro e dezembro, período no qual se verifica a diminuição expressiva da participação dos tipos de tempo Polar (DP e MP), conforme indica a Figura 2A.

Destaca-se que em Castro o tipo de tempo DT (tropical seco) ocorre com maior frequência relativa no período entre o terceiro decêndio de agosto e o primeiro decêndio de setembro $(>10 \%)$, condição possivelmente atrelada à participação das $\mathrm{mTa}$ e $\mathrm{mTc}$, em um período de transição do período seco para o chuvoso, conforme demonstram Terassi e Galvani (2018). Inclusive, no segundo decêndio de setembro, seguinte a esta maior frequência de tempo DT, verifica-se a maior frequência dos tipos de tempo MT+ (tropical úmido mais), com 16,7\% de participação. Destaca-se que se verifica a prevalência do tipo de tempo MT em períodos dispersos e sem padrão muito bem definido, como no segundo decêndio de abril e o segundo decêndio de agosto. Não foram verificados os tipos de tempo denominados MT++ (tropical úmido duplo mais), o que se atribui à continentalidade, ou seja, maior distância em relação ao Oceano Atlântico, de Castro em relação à Curitiba e à Paranaguá (Figura 2A).

Em Curitiba, nota-se que alguns padrões são similares ao observado em Castro. O tipo de tempo DP ocorre com a maior frequência entre o terceiro decêndio de maio e o segundo decêndio de junho $(>17,0 \%)$ e o tipo de tempo MP tem frequência $\geq 20 \%$ entre o segundo decêndio de abril e o terceiro decêndio de julho, basicamente caracterizando as situações mais comuns e próprias ao inverno na região Sul do Brasil (Figura 2B).

Outro padrão similar à Castro, a tipologia DM mostra uma frequência $\geq$ a $28 \%$ em todo mês de agosto e, contudo, é mais frequente no primeiro decêndio de março. Também caracterizando o período mais seco, o tipo de tempo DT é mais comum ( $\geq 8,9 \%)$ entre o segundo decêndio de agosto e os primeiros dez dias de setembro. Por sua vez, o tipo de tempo TR é superior a $11 \%$ entre o segundo decêndio de novembro e o segundo decêndio de dezembro, justamente o período em que há a redução da participação das tipologias polares. Bem como verificado em Castro, não se verifica em Curitiba a ocorrência da tipologia MT++ (Figura 2B). 
Entretanto, alguns padrões se diferem em relação à Castro, pois em Curitiba o tipo de tempo MM está associado aos períodos de transição entre as estações do ano, sendo igual ou superior a $30 \%$ no terceiro decêndio de maio (outono/inverno) e entre o primeiro decêndio de setembro e o segundo decêndio de outubro. Com exceção do verificado para o segundo decêndio de novembro, o período entre o final de outubro e o final de fevereiro corresponde ao período de maior frequência da tipologia MT, ao passo que o tipo MT+ tem sua frequência $\geq$ a $8,9 \%$ entre o segundo decêndio de outubro e o segundo decêndio de janeiro, sendo estas duas tipologias as mais associadas às condições de maiores alturas pluviais em Curitiba (Figura 2B). Estas condições de associação do período chuvoso à maior frequência da tipologia MT foram observadas por Armond (2014) e Armond e Sant'Anna Neto (2017) para a cidade do Rio de Janeiro.

Em Paranaguá, a tipologia MM é a que apresenta a maior frequência (>30\%) ao longo dos meses de maio, junho, julho, agosto, setembro e outubro, além de registrar percentuais acima de $30 \%$ nos tipos de tempo no terceiro decêndio de janeiro, nos segundo e terceiros decêndios de março, terceiro decêndio de abril e segundo decêndio de novembro, sendo assim, o estado atmosférico mais comumente associado à redução de menor pluviosidade em uma localidade que apresenta elevados totais de pluviosidade ao longo do ano todo. O tipo de tempo MT está mais diretamente associado às elevações dos totais de chuvas na área de estudo, sendo que sua frequência é menos elevada $(<10 \%)$ em todo mês de junho, nos segundo e terceiro decêndio de julho e terceiro decêndio de setembro. Por sua vez, a tipologia MT+ destaca-se pelos valores mais elevados entre o segundo decêndio de setembro e o terceiro decêndio de março ( $>20 \%)$, período no qual ocorre os mais elevados totais pluviais em Paranaguá (Figura 3).

Em Paranaguá, as mais elevadas temperaturas em relação às demais localidades é o fator preponderante para a obtenção mais restrita dos tipos de tempos polares. O tipo DP ocorre somente entre o final de abril e o final de julho, delimitando o período invernal e tem sua maior participação no primeiro decêndio de junho $(14,4 \%)$. Por exemplo, o tipo de tempo MP é expressivamente menos frequente em relação às demais localidades, sendo que entre o segundo decêndio de dezembro e o terceiro decêndio de janeiro não se verifica sua ocorrência, que tem seu ápice no segundo decêndio de maio $(21,1 \%)$. Por sua vez, a tipologia DM tem sua maior frequência $(>13 \%)$ no primeiro decêndio de agosto e terceiro decêndio de setembro, provavelmente associada à condição de transição entre o inverno e a primavera (Figura 3).

Os resultados que indicaram a prevalência dos tipos de tempo MM são similares aos obtidos por Armond (2014) para a cidade do Rio de Janeiro, na qual se identificou a maior frequência desta condição climática nos meses da estação menos chuvosa, pois sua atuação está associada à passagem da FPA. Enquanto na capital fluminense verifica-se a prevalência do tipo de tempo MT ao longo de todos os meses do ano e com uma ligeira diminuição nos meses de inverno, esta condição é verificada nas localidades avaliadas nesta pesquisa somente em alguns períodos dispersos, preeminente mais evidente na estação chuvosa em Paranaguá, localidade que apresenta semelhanças ao Rio de Janeiro devido à sua condição litorânea. Inversamente ao observado por Armond (2014), observa-se que os tipos de tempo associados à ocorrência de menores temperaturas do ar (MP) é comparativamente insignificante na cidade do Rio de Janeiro em relação às localidades estudadas pela presente pesquisa em função de uma maior atuação de mecanismos atmosféricos como a FPA e a mPa, com destaque para Castro e Curitiba.

A maior ocorrência dos tipos de tempo MP e DP associado aos sistemas atmosféricos polares é evidente em diversas pesquisas. Vanos e Cakmak (2013) mostraram a prevalência da atuação dos tipos de tempo DP e MP em diferentes setores do Canadá, embora tenha evidenciado a diminuição de sua atuação em detrimento do aumento da ocorrência de situações de tempo MT, o que os autores atribuem ao aumento de temperaturas do ar verificado generalizadamente em território canadense. Ao comparar as participações relativas dos tipos de tempo ao longo do ano em localidades dos Estados Unidos da América, Dixon et al. (2016) observou que as tipologias DP e MP prevalecem em Chicago, situado no Centro-Oeste, nos meses de outono e inverno, período no qual há uma preeminência da massa de ar polar ártica. Estes resultados são próximos aos averiguados para a área em estudo, posto que os tipos de tempo DP e MP ocorrem mais frequentemente no outono e inverno (de abril a agosto), estações nas quais a $\mathrm{mPa}$ atua mais frequentemente e fortemente na região sul do Brasil. 


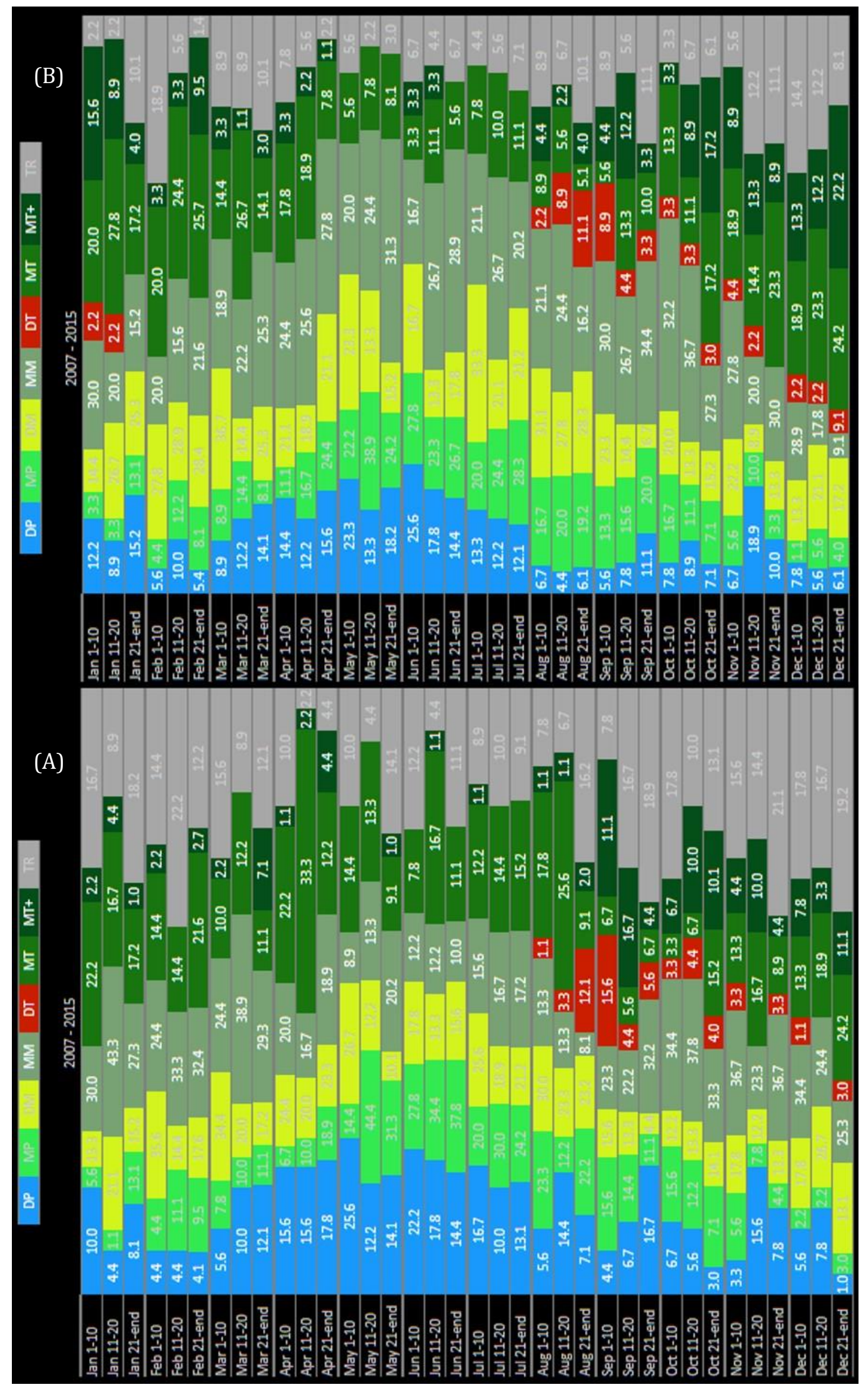

Figura 2: Frequência decendial (\%) dos tipos de tempo conforme o método SSC para a média do período de 2007 a 2015 em Castro (A) e Curitiba (B), Paraná. 


\begin{tabular}{l|c|c|c|c|c|c|}
\hline \multicolumn{1}{|c|}{ DP } & Mis & DT & MT & MT+ \\
\hline
\end{tabular}

Figura 3: Frequência decendial $(\%)$ dos tipos de tempo conforme o método SCC para a média do período de 2007 a 2015 em Paranaguá, Paraná.

Em Castro, a média de pluviosidade anual para o segmento temporal avaliado é de 1.713,8 mm. O tipo de tempo mais frequentemente associado à gênese pluvial é o MM, responsável por gerar em média 55,8\% dos totais pluviais ao longo dos anos de 2007 a 2015. Destacadamente, no ano de 2009 este tipo de tempo esteve associado a 64,5\% dos totais pluviais, ao passo que em 2007 esta participação esteve próxima a 42\%. Em média, cerca de $16 \%$ dos totais pluviais estão atrelados à condição MP, sendo que nos anos de 2010 e 2013 esta participação esteve próxima a $25 \%$ e acima dos $400 \mathrm{~mm}$. Em seguida, durante a ocorrência da tipologia MT é responsável por 10,5\% dos totais de precipitação pluviométrica em Castro ao longo da série analisada, destacando-se o ano de 2007, no qual cerca de 32,5\% das chuvas se deram a partir deste tipo de tempo, o que está associado à concentração das chuvas em cerca de $70 \%$ nos meses de verão e primavera, entre outubro e março (INMET, 2019). Por fim, as condições de transição mostraram-se responsáveis por 9,1\% dos totais de chuvas no período, com valor superior a 16\% no ano de 2011 (Figura 4A).

A condição DT, associado comumente a estabilidade atmosférica, e o MT++, que aparece com muita pouca frequência nos tipos de tempo em Castro, são as tipologias que ocasionaram os menores totais de chuva. Pela condição de estabilidade atmosférica e a sua baixa frequência relativa, nesta ordem, os tipos de tempo DP e MT+ mostraram-se favoráveis por menos de $2 \%$ dos totais pluviais. Por sua vez, o tipo de tempo 
DM mostra uma participação de 4,8\% da gênese pluvial, com totais superiores a $100 \mathrm{~mm}$ entre os anos de 2008 e 2010 e em 2015 (Figura 4A).

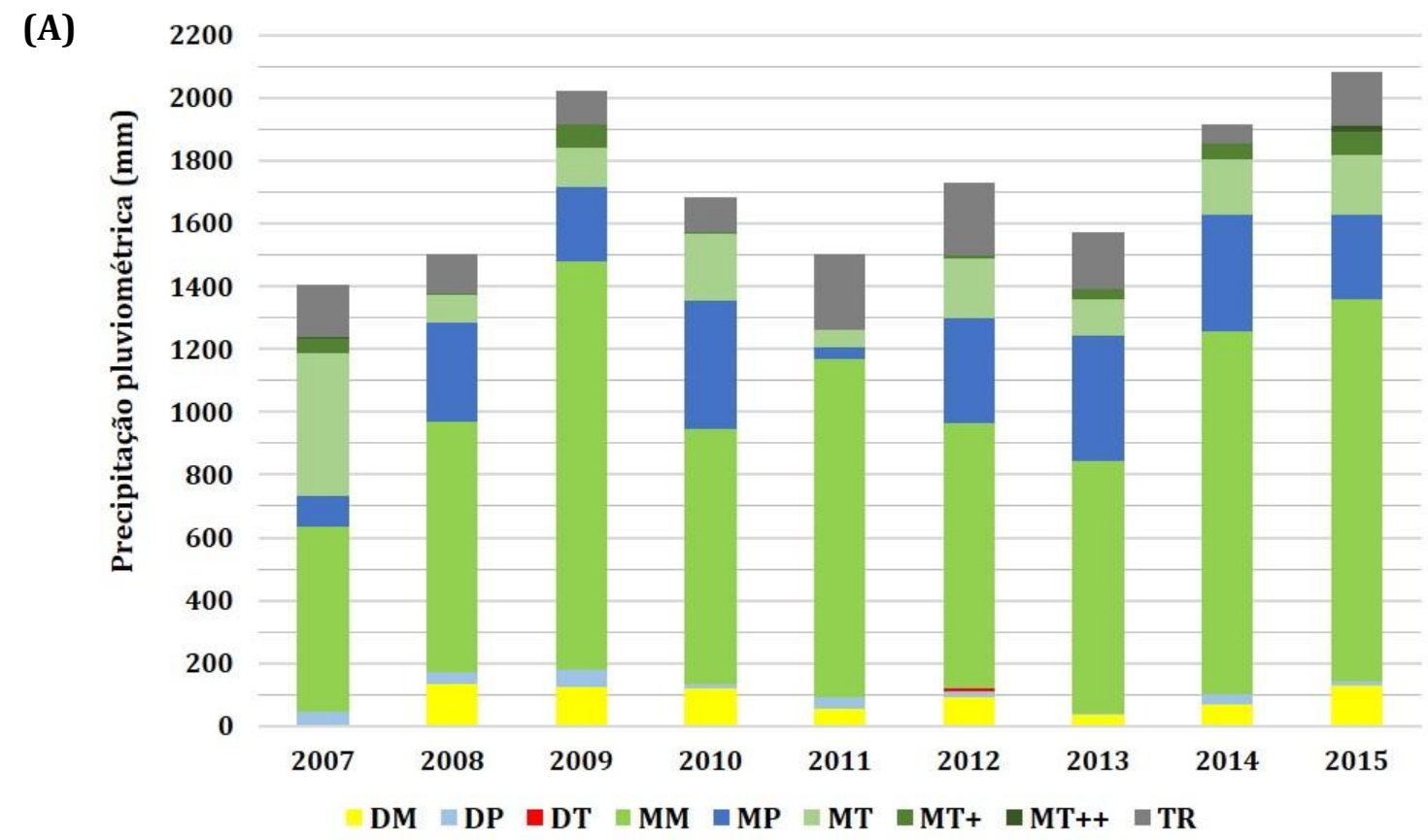

(B)

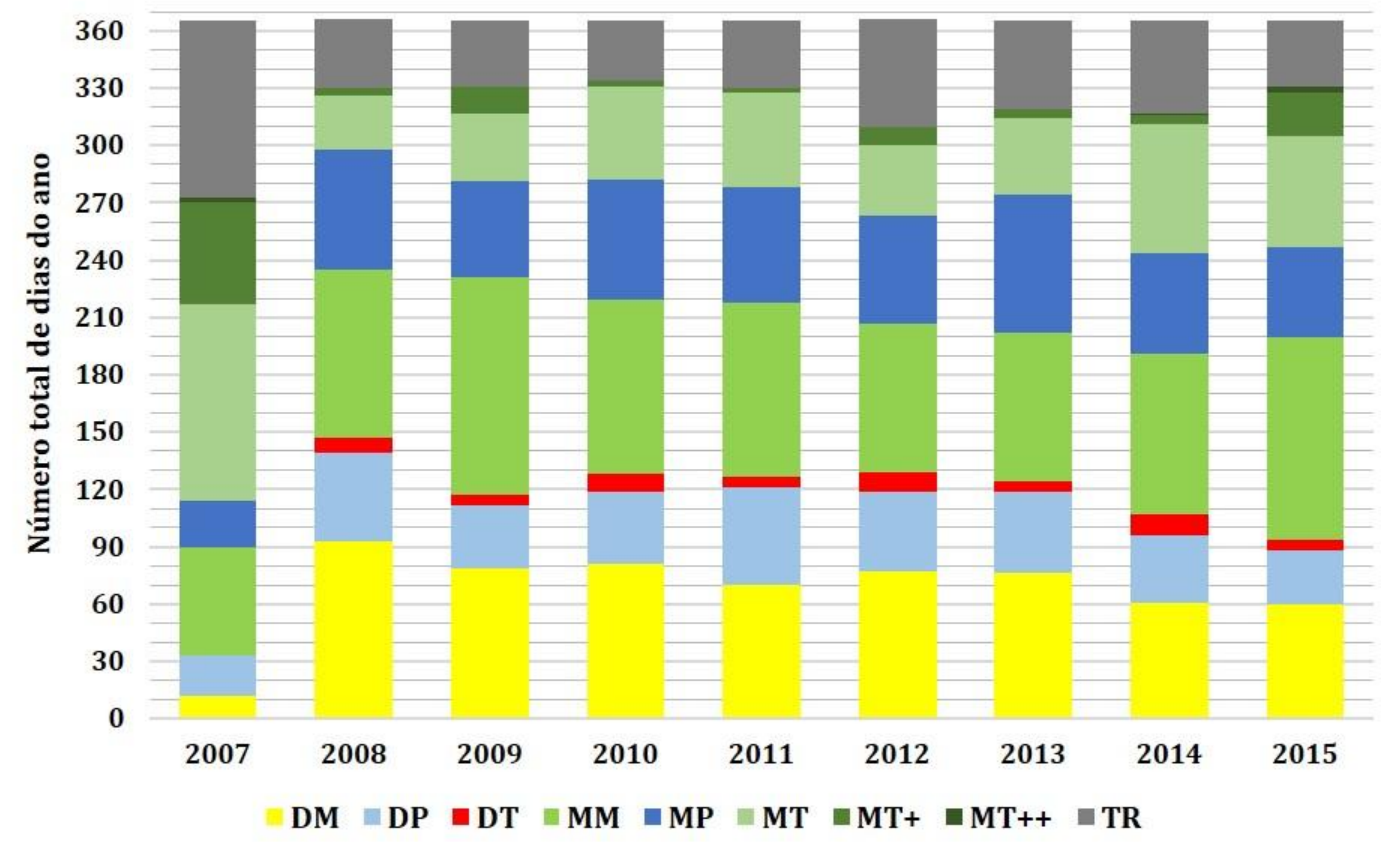

Figura 4: Gênese pluvial (A) e frequência dos tipos de tempo (B) em Castro, Paraná, entre 2007 e 2015.

Em relação à frequência absoluta dos tipos de tempo, observa-se que em Castro aproximadamente cerca de 87 dias do ano em média estiveram em condições MM e, em seguida, 68 dias mostraram a tipologia DM. Nota-se o predomínio do tipo de tempo MM no período entre 2009 e 2015, sendo superior a 100 dias nos anos de 2009 e 2015, os quais obtiveram totais de pluviosidade superior a $2.000 \mathrm{~mm}$. Dentre os anos de menores totais pluviométricos $(\leq 1.500 \mathrm{~mm})$, verificou-se o predomínio da tipologia MT e DM nos anos de 2007 e 2008, ordenadamente (Figura 4B).

Ao longo dos nove anos analisados, a média pluvial anual em Curitiba é de 1.730,8 mm. Observa-se que em média $43,0 \%$ dos totais pluviométricos se deram em condições da tipologia MM, tendo sido mais frequente nos anos de 2009 e 2015, com uma média de 53,0\% e 59,8\% da participação na geração dos totais anuais, nesta ordem. O tipo de tempo polar úmido mostra-se como o segundo mais efetivo, com uma média de 18,2\% dos totais pluviais do período analisado, sendo que em 2010 este percentual foi de 27,1\%. Em seguida, o MT é o terceiro tipo de tempo com a maior participação média na geração das chuvas (15,5\%) e, 
contudo, em 2007 este valor chegou a 27,2\%, semelhante ao observado em Castro. As condições de transição (TR) foram responsáveis por 8,9\% do total pluvial médio, superando os 20\% no ano de 2013 (Figura 5A).

Em Curitiba, os tipos de tempo MT++ e DT foram responsáveis por uma média dos totais pluviométricos inferiores a $1 \%$ e, portanto, são as tipologias com a menor frequência na geração das chuvas. O tipo de tempo MT+ mostra-se atuante em cerca de 5\% do total precipitado, superando os $10 \%$ em 2009. Observa-se que as tipologias DM e DP estiveram atuantes em 5,7\% e 2,8\% do volume total e no ano de 2012 mostraram as suas atuações mais eficazes, com uma participação de 12,4\% e 8,2\%, nesta ordem (Figura 5A).
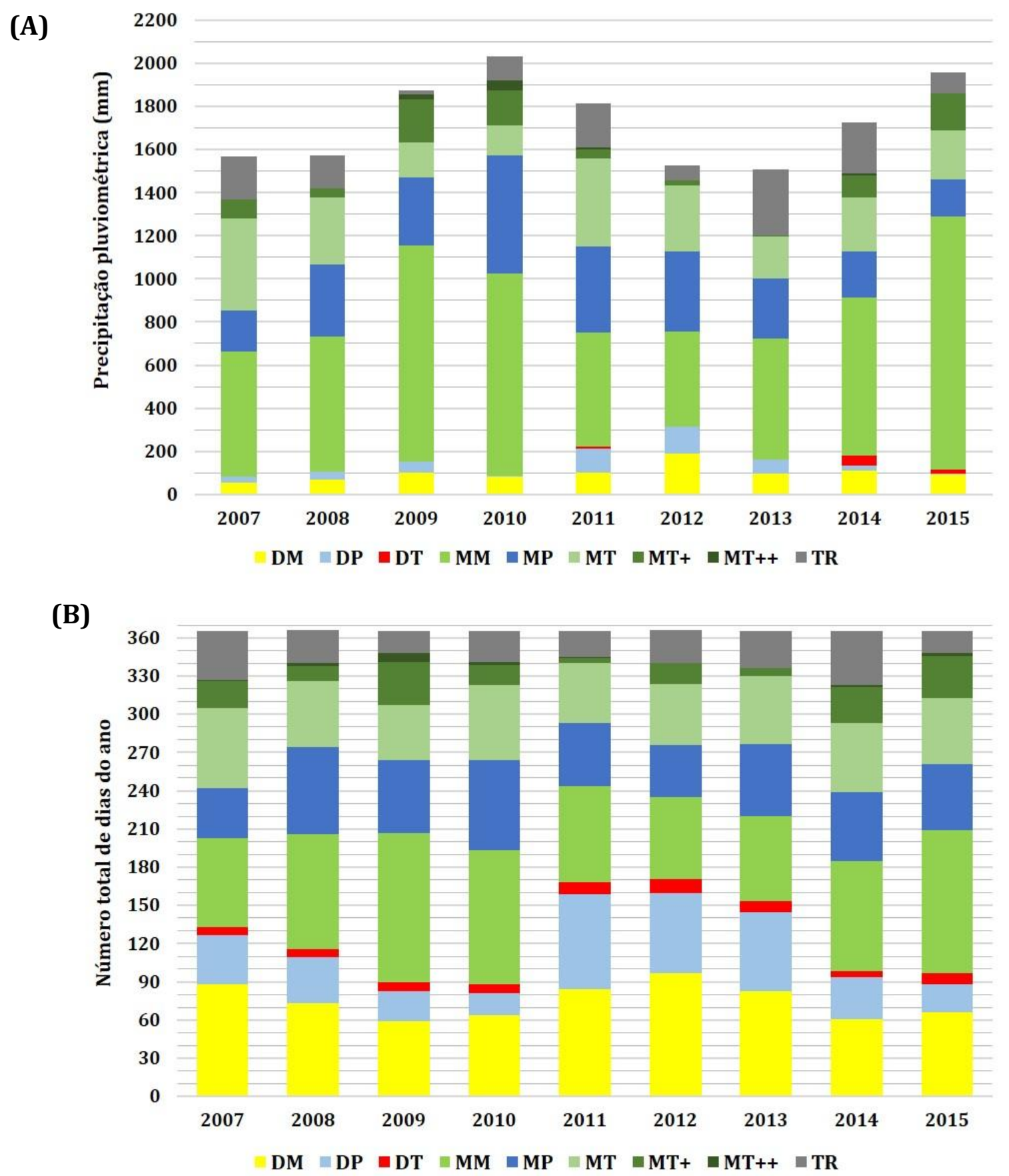

Figura 5: Gênese pluvial (A) e a frequência dos tipos de tempo (B) em Curitiba, Paraná, entre 2007 e 2015.

Observa-se que na capital paranaense predomina o tipo de tempo MM, com uma média de 88 dias ao ano, tendo sido superior a 90 dias em 2008, 2009, 2010 e 2015, anos nos quais os totais de precipitação pluvial é superior a $1.800 \mathrm{~mm}$, com exceção do ano de 2008. Em seguida, o tipo de tempo DM ocorre em média 75 dias ao ano e superior a 80 dias em 2007, 2011, 2012 e 2013, sendo que com exceção do ano de 2011, notase em todos estes anos uma pluviosidade total anual inferior a $1.600 \mathrm{~mm}$. O tipo de tempo menos frequente é o MT++ ocorre com a menor frequência, em média de 2 dias ao ano, e mais frequente em 2009 (07 dias), no qual verificou-se o maior percentual de chuvas decorrentes deste tipo de tempo (Figura 5B). 
Outras tipologias, como MP e MT ocorreram com uma frequência superior a 50 dias em média ao ano. O ano de 2011 caracterizou-se pela maior frequência da tipologia MP (71 dias), enquanto em 2010 observou-se a maior participação do tipo de tempo MT (59 dias). Dentre os aspectos mais relevantes, aponta-se que o ano de 2011 também foi caracterizado pela maior frequência da tipologia DP, sugerindo uma provável elevada participação dos sistemas atmosféricos polares $(\mathrm{mPa})$ ao longo deste ano (Figura 5B).

Para o segmento temporal de 2007 a 2015, a precipitação pluviométrica média anual em Paranaguá é de $2.322,3 \mathrm{~mm}$. Isoladamente, o tipo de tempo MM é o que apresenta a maior participação na gênese pluvial (48,6\%), sendo que para o ano de 2008 este valor superou os $60 \%$, sendo o ano de maior participação desta tipologia. Em seguida, a tipologia MT apresenta uma média de 21,1\% na gênese pluvial, com valores que superaram os $27 \%$ nos anos de 2008 e 2011. Com 8,8\% de participação na gênese pluvial deste período em análise, o tipo de tempo TR apresentou valores superiores a 13\% nos anos de 2014 e 2015 (Figura 6A).

Com uma média de $8,6 \%$ de participação na gênese pluvial, a tipologia MP foi responsável pela ocorrência de $28,5 \%$ da precipitação pluviométrica verificada em 2015. Com uma expressiva variabilidade ao longo dos anos, a tipologia MT+ aparece como o tipo de tempo responsável por 7,2\% dos totais pluviais no período avaliado, sendo que no ano de 2009 este valor superou os $14 \%$, contrapondo-se ao observado em 2015, no qual este valor foi inferior a $0,01 \%$ (Figura 6A).

Tendo a atuação do tipo de tempo DM, observa-se uma gênese pluvial equivalente a 3,3\%, chegando a cerca de 19\% (>500 mm) no ano de 2015 e, bem como a tipologia DM, apresenta uma expressiva variabilidade, com valor inferior a $0,05 \%(0,2 \mathrm{~mm})$ em 2012. O tipo de tempo MT++ gerou 1,8\% dos totais de pluviosidade, sendo que 2007 esta participação esteve em 6,4\%. A tipologia DP mostra-se atuante para a geração de somente $0,5 \%$ dos totais pluviais, com uma participação de $2,25 \%$ no ano de 2015 . Por fim, a tipologia DT não foi verificada em nenhum dia do período analisado e, desta forma, não esteve atuante em nenhuma condição de chuva (Figura 6A).

As características tropicais úmidas foram responsáveis pelos tipos de tempo de 159 dias em média, destacando-se que os tipos de tempo mais comuns é o MT (94 dias) e MT+ (50 dias). Devido ao efeito da maritimidade, nota-se a maior frequência do tipo de tempo MT++ (15 dias) em relação às demais localidades. No entanto, o tipo de tempo mais comum é o MM, com uma média de 122 dias, amplamente relacionada às condições de ocorrência de chuvas. As condições de Transição (TR) estiveram atuantes em média de 34 dias e moderadamente seco (DM) em 23 dias. Por fim, o tipo de tempo polar seco (DP) esteve atuante em média durante 8 dias (Figura 6B).

Observa-se que a tipologia MM foi identificada mais frequentemente e superior a 140 dias em 2008, 2011 e 2013, enquanto o tipo de tempo MT se mostra superior a 120 dias nos anos de 2008 e 2014. Apesar da alta pluviosidade (>2.700 mm), o ano de 2015 apresentou com maior frequência as tipologias DM (120 dias), TR (57 dias) e DP (25 dias). Em 2009, verifica-se a maior frequência absoluta do número de dias com as tipologias MT+ (68 dias) e MT++ (34 dias), ressaltando-se a influência destes tipos de tempo para a gênese pluvial deste ano, que somadas geraram cerca de $20 \%$ dos totais de pluviosidade (Figura 6B).

Estes resultados são condizentes com aqueles observados por Terassi e Galvani (2017a), Terassi e Galvani (2017b) e Terassi (2019) em relação às características da precipitação pluviométrica no setor leste do estado do Paraná. Estes estudos discorreram que a bacia Litorânea, na qual está situada a localidade de Paranaguá, caracteriza-se pelos mais elevados totais pluviométricos do estado do Paraná (>2.000 mm anuais) devido à frequente atuação da Frente Polar Atlântica associada às condições mais propícias à geração de chuvas em decorrência das mais elevadas temperaturas e do maior potencial higrométrico devido à proximidade ao Oceano Atlântico, conforme destacado por Mello et al. (2017). O setor continente adentro, especificamente em Curitiba e em Castro, apresenta uma menor influência da maritimidade em virtude da barreira orográfica da Serra Mar e a geração de chuvas está associada mais restritamente à Frente Polar Atlântica e aos tipos de tempo moderado úmido (MM). 

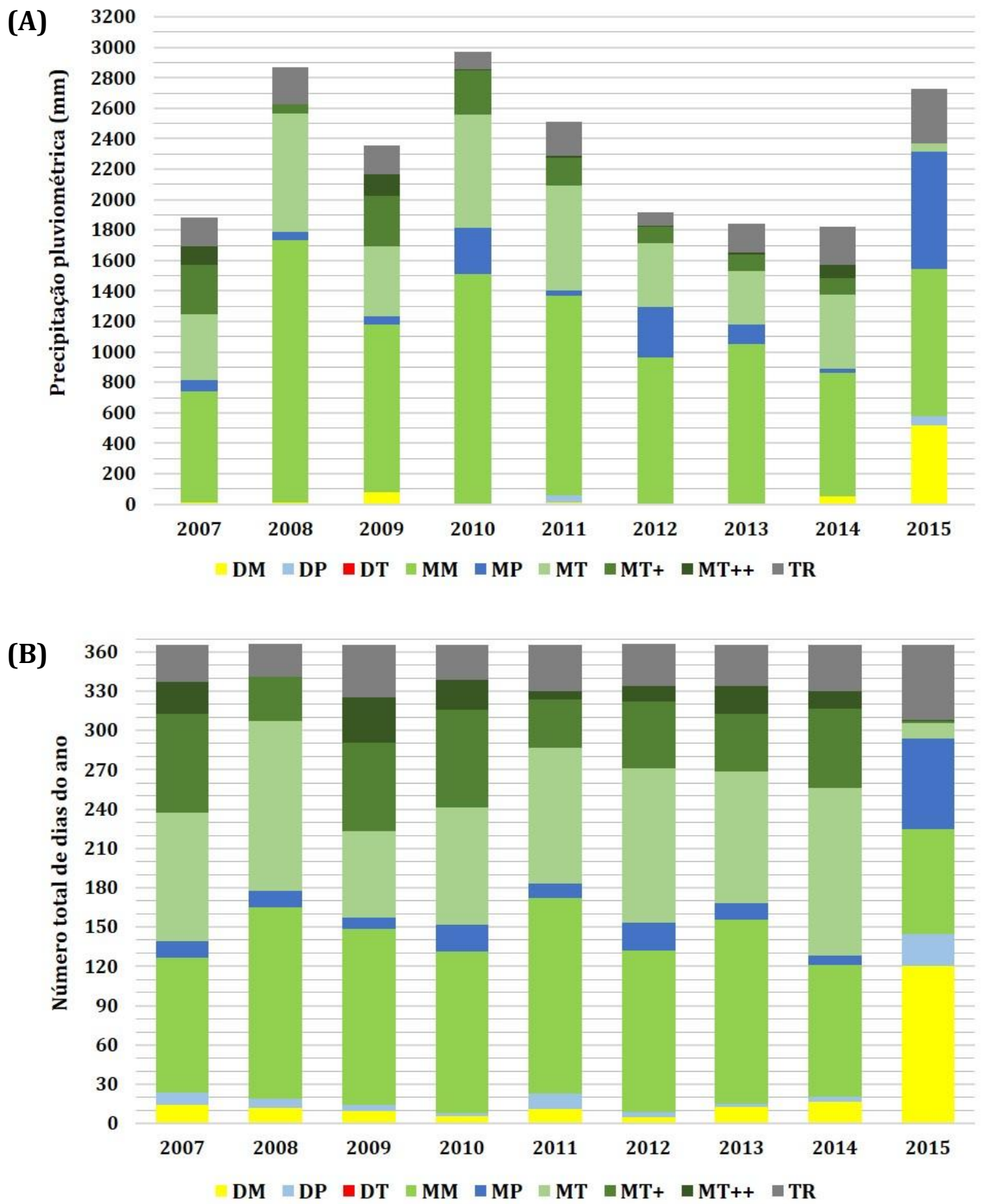

Figura 6: Gênese pluvial (A) e a frequências dos tipos de tempo (B) em Paranaguá, Paraná, entre 2007 e 2015.

A análise realizada a partir da SCC para a cidade de São Paulo realizada por Fontão et al. (2018) mostrou a prevalência das tipologias MM, MT e MT+ para geração das chuvas, sobretudo para o período do verão e da primavera, período em que há uma maior participação dos sistemas atmosféricos intertropicais na gênese pluvial, ao passo que as tipologias MP e TR foram mais frequentemente como responsáveis pela ocorrência das chuvas no período de outono e inverno. Com a utilização da técnica dos anos-padrão, o autor supracitado destacou o ano de 2010, classificado como chuvoso e com uma maior participação dos tipos de tempo MT e MT+ na gênese das chuvas em comparação ao ano de 2014, resultado contrário ao obtido para Curitiba e Castro, que se caracterizam por uma atuação mais incisiva dos sistemas atmosféricos extratropicais em relação à capital paulistana.

Dado o caráter subtropical da área em estudo pela presente pesquisa, observou-se uma maior participação dos tipos de tempo polares em relação ao observado por Armond (2014) para o Rio de Janeiro. Segundo a autora, o período chuvoso (outubro a março) no Rio de Janeiro é marcado pela predominância do tipo de tempo MT (úmido tropical), sendo que esta tipologia obteve uma maior ocorrência em Paranaguá em relação às duas demais localidades em virtude das condições de similar localização em uma área litorânea, mais quente e úmida, como é a capital fluminense. Armond (2014) também ressalta que predominância dos tipos 
MT e MM (úmido moderado) denotam a presença de umidade e temperaturas elevadas durante todo o ano, característica peculiar do Rio de Janeiro, e que os tipos DT (seco tropical), DM (seco moderado) e DP (seco polar) foram encontrados nos meses da estação menos chuvosa, sendo que este último tipo de tempo está diretamente atrelado à atuação da massa de ar Polar atlântica e sua repercussão em condições de estabilidade atmosférica, redução da umidade relativa do ar e menores temperaturas do ar.

Comparativamente, Hebbern e Cakmak (2015) aplicaram a SCC em diferentes localidades do território canadense e identificaram que os tipos de tempo seco moderado (DM) e úmido moderado (MM) são os mais frequentes em todas as cidades, enquanto os menos comuns são os tipos de clima seco tropical (DT) e tropical úmido (MT), dadas as condições dos climas temperados, frios e polares. Por sua vez, o tipo de tempo polar seco (DP) ocorre mais frequentemente nas áreas menos úmidas do território, sobretudo no setor leste e nas pradarias canadenses e associado às condições de dominância da massa de ar Polar ártica, e menos prevalecentes em Vancouver e Toronto, localidades com climas mais úmidos e menos frios em comparação às demais regiões canadenses. Portanto, verifica-se que a menor frequência da tipologia DP para Paranaguá está diretamente ligada à influência marítima e de condições de temperatura mais elevadas e maior umidade em comparação à Curitiba e, especialmente, à Castro.

Greene (1996) discorre que os tipos de tempo MT e MM são mais comumente associados à ocorrência de chuvas na região sudeste dos Estados Unidos da América, região na qual se verifica a predominância do clima Subtropical ("Cfa") e semelhante ao verificado em Paranaguá. Este autor verificou que o tipo de tempo MT (tropical úmido) esteve correlacionado aos eventos de chuvas de origem convectiva, enquanto o tipo de tempo MM (moderado úmido) foi identificado quando as precipitações resultaram da atuação dos sistemas frontais. Associando aos resultados obtidos pela presente pesquisa, as localidades estudadas apresentaram a predominância do tipo de tempo MM para a gênese pluvial, posto que a Frente Polar Atlântica é o principal mecanismo de geração de chuvas na região, com uma participação considerável dos tipos de tempo MT em Paranaguá, devido a sua condição de maiores temperaturas médias do ar e a influência da maritimidade, aspecto que responde pelo aumento dos totais pluviais no setor litorâneo do estado do Paraná, especialmente no meses de verão, conforme indicaram Terrassi e Galvani (2018).

Bower et al. (2007) mostraram que a ocorrência de verões chuvosos com a frequência reduzida de dias secos consecutivos no setor ocidental da Europa esteve diretamente atrelada aos tipos de tempo MM e MP e, contudo, destacaram que as chuvas mais intensas ocorreram quando se verificou a tipologia MT, decorrente do ar úmido advectado vindo do setor meridional da Europa. Para o setor leste do estado do Paraná, observou-se que a gênese pluvial esteve majoritariamente sob condições de tipos de tempo MM, sobretudo com a atuação dos sistemas frontais e, entretanto, os totais anuais de maiores valores se deram em Paranaguá, localidade onde há uma maior participação do tipo de tempo MT. Observou-se a dominância dos tipos de tempo MP e DP para o período de inverno em situação similar a verificada em Castro e Curitiba, nas quais são verificadas as menores temperaturas do ar devido à atuação incisiva do Anticiclone Migratório Polar ao longo dos meses invernais.

\section{Considerações finais}

A utilização do método híbrido "Spatial Synoptic Classification" (SSC) demonstrou satisfatoriamente as principais diferenças dos tipos de tempo entre as três localidades, embora sejam reconhecidas as restrições do nível de detalhamento sobre as características dos mecanismos atmosféricos atuantes frente aos que podem ser apresentados pela consagrada Análise Rítmica. Enquanto em Paranaguá não se verifica a ocorrência do tipo de tempo DT (tropical seco), o que está atrelado à influência da maritimidade, em Castro e Curitiba este tipo ocorre com uma frequência maior entre o final de agosto e meados de setembro, sendo associado ao tempo quente e seco, sendo características da atuação da massa Tropical continental. Os tipos de tempo MT, MT+ e MT++ ocorreram com maior frequência em Paranaguá em relação as demais localidades, justamente devido às mais elevadas temperaturas e a influência da maritimidade para o aumento da umidade relativa do ar. Os tipos de tempo polares (DP e MP) ocorreram com maior frequência entre o final de abril e o final de julho em todas as estações meteorológicas, relacionadas à atuação à mais frequente atuação da massa Polar atlântica e à Frente Polar Atlântica.

Quanto à gênese pluvial, verificou-se que o tipo de tempo frequentemente mais associado à ocorrência de chuvas é o moderado úmido (MM), que em Castro chega a até 55,8\% do total pluviométrico médio anual. Contudo, o segundo tipo de tempo frequentemente mais associado à gênese pluvial é o Moist Polar (MP) para Castro (16,0\%) e em Curitiba $(18,2 \%)$ e, contudo, em Paranaguá o segundo tipo de tempo que atua com maior intensidade e frequência na geração das chuvas é o MT (Moist Tropical), associado às mais elevadas temperaturas, à influência da maritimidade e, principalmente, ao aumento expressivo dos volumes de chuvas 
no período do verão, posto que em Paranaguá entre janeiro e março, as médias mensais são superiores a 300 $\mathrm{mm}$.

Diante do proposto pelos objetivos, espera-se que os resultados e discussões dispostos acima contribuam para o conhecimento da dinâmica atmosférica e da gênese pluvial do setor leste do estado do Paraná. Sendo assim, esta pesquisa incorporou os detalhes de uma investigação norteada a partir das características meteorológicas das massas de ar e não de suas regiões geográficas de origem e, desta forma, analisa os mecanismos atmosféricos responsáveis pelos diferentes tipos de tempo e, destacadamente, pela formação e geração das chuvas em cada uma das localidades investigadas.

\section{Notas}

Este manuscrito refere-se em partes aos resultados obtidos pela tese de doutoramento do autor principal sob a orientação do segundo autor, intitulada "Variabilidade pluviométrica e os eventos pluviais extremos em bacias hidrográficas no leste do estado do Paraná", defendida em como requisito para a obtenção do título de Doutor em Ciências pelo Programa de Pós-Graduação em Geografia Física, pertencente ao Departamento de Geografia da Universidade de São Paulo.

\section{Agradecimentos}

O presente trabalho foi realizado com apoio do Programa Nacional de Cooperação Acadêmica (PROCAD) da Coordenação de Aperfeiçoamento de Pessoal de Nível Superior (CAPES) - Edital 071/2013 processo número 88881.068465/2014-01. O autor principal agradece à CAPES pela concessão da bolsa de Doutorado e ao Conselho Nacional de Desenvolvimento Científico e Tecnológico (CNPq) pela concessão da bolsa de Pós-Doutorado Júnior (PDJ - Processo: 165450/2020-7). O segundo autor agradece ao CNPq pela concessão da bolsa de Produtividade em Pesquisa (Nível 1D - Processo: 304973/2017-3). Agradecemos com estimas ao Professor Doutor Scott Christopher Sheridan (Kent State University) e à Professora Doutora Núbia Beray Armond (Universidade Federal do Rio de Janeiro), que foram primordiais para a elaboração dos resultados concernentes à Spatial Synoptic Classification. Agradecemos aos revisores pelas valiosas contribuições para o desenvolvimento desta pesquisa.

\section{Referências}

ARMOND, N.B. Entre eventos e episódios: as excepcionalidades das chuvas e os alagamentos no espaço urbano do Rio de Janeiro. 2014. 239f. Dissertação (Mestrado). Programa de Pós-Graduação em Geografia. Universidade Estadual Paulista “Júlio de Mesquita Filho”, Presidente Prudente, 2014.

ARMOND, N.B.; SANT'ANNA NETO, J.L. Entre eventos e episódios: ritmo climático e excepcionalidades para uma abordagem geográfica do clima no município do Rio de Janeiro. Revista Brasileira de Climatologia, v.20, n.13, p.5-28, 2017. DOI: 10.5380/abclima.v20i0.49792

ÁlVARES, C.A.; STAPE, J.L.; SENTELHAS, P.C.; DE MORAES GONÇALVES, J.L.; SPAROVEK, G. Köppen's climate classification map for Brazil. Meteorologische Zeitschrift, v.22, n.6, p.711-728, 2013. DOI: 10.1127/0941-2948/2013/0507

BORSATO, V.A.; MENDONÇA, F.A. Participação da massa polar atlântica na dinâmica dos sistemas atmosféricos no Centro Sul do Brasil. Mercator, v.14, n.1, p.113-130, 2015. DOI: 10.4215/RM2015.1401.0 008

BOWER, D.; MCGREGOR, G.R.; HANNAH, D.M.; SHERIDAN, S.C. Development of a spatial synoptic classification scheme for western Europe. International Journal of Climatology, v.27, n.15, p.2017-2040, 2007. DOI: $10.1002 /$ joc. 1501

CARDOZO, A.B.; REBOITA, M.S.; GARCIA, S.R. Climatologia de Frentes Frias na América do Sul e sua relação com o Modo Anular Sul. Revista Brasileira de Climatologia, v.17, p.9-29, 2015. DOI:10.5380/abcl ima.v17i0.40124

CUPOLILLO, F.; ABREU, M.L.; VIANELLO, R.L. Climatologia da bacia do rio doce e sua relação com a topografia local. Geografias, v.4, n.1, p.45-60, 2008. DOI: 10.356992237-549X\%20..13251 
DIXON, P.G.; ALLEN, M.; GOSLING, S.N.; HONDULA, D.M; INGOLE, V., LUCAS, R.; VANOS, J. Perspectives on the synoptic climate classification and its role in interdisciplinary research. Geography Compass, v.10, n.4, p.147-164, 2016. DOI: 10.1111/gec3.12264

DYER, J.L.; MOTE, T.R. Trends in snow ablation over North America. International Journal of Climatology, v.27, n.6, p.739-748, 2007. DOI: 10.1002/joc.1426

FONTÃO, P.A.B.; ZAVATTINI, J.A.; SHERIDAN, S.C.; ARMOND, N.B. Gênese das chuvas em São Paulo (SP): estudo comparativo entre a "Spatial Synoptic Classification" e a "Análise Rítmica em Climatologia”. Revista Brasileira de Climatologia, v.23, n.14, p.267-288, 2018. DOI: 10.5380/abclima.v23i0.58657

FONTÃO, P.A.B.; ZAVATTINI, J.A. Variations of rainfall rhythm in Alto Pardo watershed, Brazil: Analysis of two specific years, a wet and a dry one, and their relation with the river flow. Climate, v.5, n.3, p. 47, 2017. DOI:10.3390/cli5030047

FRITZSONS, E.; MANTOVANI, L.E.; WREGE, M.S.; CHAVES NETO, A. Análise da pluviometria para definição de zonas homogêneas no estado do Paraná. RA'E GA: o Espaço Geográfico em Análise, v.23, n.1, p.555-572, 2011. DOI: 10.5380/raega.v23i0.24921

GREENE, S.J. A synoptic climatological analysis of summertime precipitation intensity in the eastern United States. Physical Geography, v.17, n.5, p.401-418, 1996. DOI: 10.1080/02723646.1996.10642592

HEBBER, C.; CAKMAK, S. Synoptic weather types and aeroallergens modify the effect of airpollu-tion on hospitalisations for asthma hospitalisations in Canadiancities. Environmental Pollution, v. 204, 2015. DOI: 10.1016/j.envpol.2015.04.010

HONDULA, D.M.; SITKA, L.; DAVIS, R.E.; KNIGHT, D.B.; GAWTRY, S.D.; DEATON, M.L.; LEE, T.R.; NORMILE, C.P.; STENGER, P.J. A back-trajectory and air mass climatology for the Northern Shenandoah Valley, USA. International Journal of Climatology, v.30, n.4, p.569-581, 2009. DOI: 10.1002/joc .1896

HONDULA, D.M.; DAVIS, R.E. Decline in wintertime air-mass transition frequencies in the USA. Climate Research, v.46, n.2, p.121-136, 2011. DOI:10.3354/cr00971

HONDULA, D.M.; VANOS, J.K.; GOSLING, S.N. The SSC: a decade of climate-health research and future directions. International Journal of Biometeorology, v.58, n.2, p.109-120, 2014. DOI: 10.1007/s00484012 $-0619-6$

IBGE (Instituto Brasileiro de Geografia e Estatística). Cidades@. Disponível em: < https://cidades.ibge.gov. br/brasil/pr/curitiba/panorama>. Acesso em 25 de abril de 2020.

INMET (Instituto Nacional de Meteorologia). Gráficos Climatológicos. 2018. Disponível em: <http:/www.i net.gov.br/portal/index.php?r=clima/graficosClimaticos>. Acesso em 28 de fevereiro de 2018.

JORGE, F.V.; MENDONÇA, F.A. O clima da fachada atlântica sul do Brasil: uma atualização introdutória. Revista Brasileira de Climatologia, v.5, n.5, p.119-131, 2009. DOI: 10.5380/abclima.v5i0.50481

KALKSTEIN, L.S.; NICHOLS, M.C.; BARTHEL, C.D.; GREENE, J.C. A new spatial synoptic classification: application to air mass analysis. International Journal of Climatology, v.16, n.9, p.9831004, 1996. DOI: 10.1002/(SICI)1097-0088(199609)16:9<983::AID-JOC61>3.0.CO;2-N

KALKSTEIN, L. S.; SHERIDAN, S.; GRAYBEAL, D. A determination of character and frequency changes in air masses using a Spatial Synoptic Classification. International Journal of Climatology, v.18, n.11, p.1223-1236, 1998. DOI: 10.1002/(SICI)1097-0088(199809)18:11<1223::AID-JOC310>3.0.CO;2-1

KELLER FILHO, T.; ASSAD, E.D.; LIMA, P.R.S.R. Regiões pluviometricamente homogêneas no Brasil. Revista Brasileira de Pesquisa Agropecuária, v.40, n.4, p.311-322, 2005. DOI: 10.1590/S0100204X20050 00400001 
KÖPPEN, W. Das geographische System der Klimate. IN: KÖPPEN, W., R. GEIGER (Orgs.). Handbuch der Klimatologie. Gebrüder Bornträger: Berlin, 1936, v. 1, parte C, p.1-44.

LEATHERS, D.J.; MOTE, T.L.; GRUNDSTEIN, A.J.; ROBINSON, D.A.; FELTER, K.; CONRAD, K.; SEDYWITZ, L. Associations between continental-scale snow cover anomalies and air mass frequencies across eastern North America. International Journal of Climatology, v.22, n.12, p.1473-1494, 2002. DOI: $10.1002 /$ joc. 807

MAACK, R. Geografia Física do Estado do Paraná. $4^{a}$ Edição. Ponta Grossa: Editora UEPG. 2012. 526p.

MELLO, Y.R.; LOPES, F.C.A.; ROSEGHINI, W.F.F. Características climáticas e análise rítmica aplicada a episódios extremos de precipitação e temperatura no município de Paranaguá, PR. Revista Brasileira de Climatologia, v.20, n.1, p.313-336, 2017. DOI:10.5380/abclima.v20i0.48594

MONTEIRO, C.A.F. Análise rítmica em climatologia: problemas da atualidade climática em São Paulo e achegas para um programa de trabalho. Climatologia. São Paulo, 1971. 21p.

NASCIMENTO-JÚNIOR, L.; SILVESTRE, M.; SANT'ANNA NETO, J.L. Trends and rainfall tropicalizetion in Paraná State, south of Brazil. Atmosféra, v.33, n.1, p.1-18, 2020. DOI: 10.20937/ATM.52441

NERY, J.T.; CARFAN, A.C. Re-analysis of pluvial precipitation in southern Brazil. Atmosféra, v.27, n.2, p. 103-114, 2014. DOI: 10.1016/S0187-6236(14)71104-X

REBOITA, M.S.; GAN, M.A.; ROCHA, R.P.; AMBRIZZI, T. Regimes de precipitação na América do Sul. Revista Brasileira de Meteorologia, v.25, n.2, p.185-204, 2010. DOI: 10.1590/S0102-77862010000200004

SHERIDAN, S. The redevelopment of a weather-type classification scheme for North America. International Journal of Climatology, v. 22, n.1, p.51-68, 2002. DOI: 10.1002/joc.709

SHERIDAN, S.C.; KALKSTEIN, A.J. Seasonal variability in heat-related mortality across the United States. Natural Hazards, v.55, n.2, p.291-305, 2010. DOI: 10.1007/s11069-010-9526-5

TERASSI, P.M.B.; GALVANI, E. Identification of Homogeneous Rainfall Regions in the Eastern Watersheds of the State of Paraná, Brazil. Climate, v.5, n.3, p.53-65, 2017a. DOI: 10.3390/cli5030053

TERASSI, P.M.B.; GALVANI, E. O efeito orográfico da Serra do Mar e o potencial erosivo das chuvas nas bacias hidrográficas do Ribeira e Litorânea - Paraná. Revista Brasileira de Climatologia, v.21, n.1, p.327345, 2017b. DOI:10.5380/abclima.v21i0.47621

TERASSI, P.M.B.; GALVANI, E. Análise da frequência e da intensidade das precipitações diárias extremas em Curitiba e Paranaguá-Paraná, Brasil. In: GALVANI, E.; GOBO, J.P.A.; LIMA, N.G.B. (Org.). Climatologia Aplicada II. 1ª Edição. Curitiba: CRV, 2018, v.1, p.181-190, 2018.

TERASSI, P.M.B. Variabilidade pluviométrica e os eventos pluviais extremos em bacias hidrográficas do leste do estado do Paraná. 2019. 293f. Tese (Doutorado). Programa de Pós-Graduação em Geografia Física, Departamento de Geografia, Faculdade de Filosofia, Letras e Ciências Humanas, Universidade de São Paulo, 2019.

URBAN, A.; KYSELÝ, J. Application of spatial synoptic classification in evaluating links between heat stress and cardiovascular mortality and morbidity in Prague, Czech Republic. International Journal of Biometeorology, v.62, n.1, p.85-96, 2015. DOI: 10.1007/s00484-015-1055-1

VANOS, J.K.; CAKMAK, S.; BRISTOW, C.; BRION, V.; TREMBLAY, N.; MARTIN, S.; SHERIDAN, S.S. Synoptic weather typing applied to air pollution mortality amongthe elderly in 10 Canadian cities. Environmental Research, v.126, p.66-75, 2013. DOI: 10.1016/j.envres.2013.08.003 
VANOS, J.K. CAKMAK. Changing air mass frequencies in Canada: potential linksand implications for human health. International Journal of Biometeorology, v.58, n.2, p.121-135, 2014. DOI: $10.1007 / \mathrm{s} 00484-013-0634-2$

WREGE, M.S.; FRITZSONS, E.; CARAMORI, P. H.; RICCE, W.S.; RADIN, B.; STEINMETZ, S.; REISSER JÚNIOR, C. Regiões com similaridade de comportamento hídrico no Sul do Brasil. RA'E GA: o Espaço Geográfico em Análise, v.38, n.1, p.363-382, 2016. DOI: 10.5380/raega.v38i0.43037

YARNAL, B.; COMRIE, A.C.; FRAKES, B.; BROWN, D.P. Developments and prospects in synoptic climatology. International Journal of Climatology, v.21, n.15, p.1923-1950, 2001. DOI: 10.1002/joc.675.

(1) (5) (2)

BY 